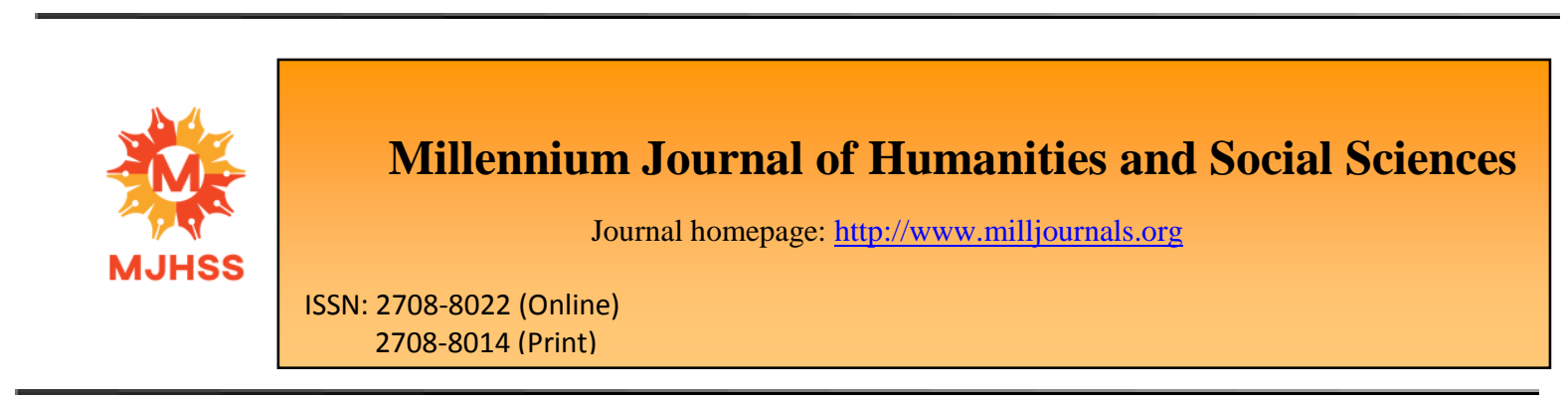

حوكمة الثركات: كمدخل لمكافحة الفساد

$$
\begin{aligned}
& \text { قاني الثقران الثعانية، كلية العلوم والآداب، جامعة العلوم والتكنولوجيا، الاردن } \\
& \text { https://doi.org/10.47340/mjhss.v1i1.5.2020 }
\end{aligned}
$$

$$
\begin{aligned}
& \text { تهذف هذه: الدر اسة إلى بيان دور الحوكمة المؤسسية في الثركات في مكافحة الفساد، وذلك لما لهذا الموضوع من الهـ أهمية كبيرة في }
\end{aligned}
$$

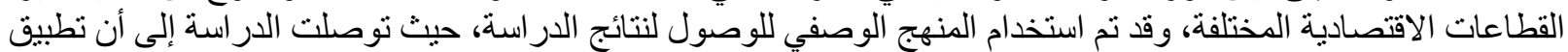

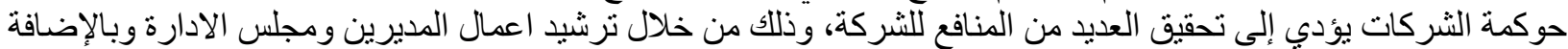

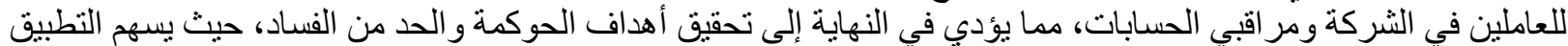

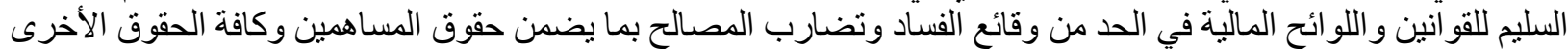

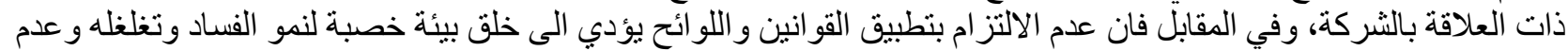

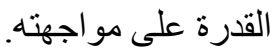

$$
\begin{aligned}
& \text { الكلمات المفتاحية: الحوكمة، الثركات، الفساد، أصحاب المصالح }
\end{aligned}
$$

\title{
Hani Alshogran
}

\section{Corporate Governance: An Approach to Anti-Corruption}

Department of Humanities, Faculty of Science and Arts, Jordan University of Science and Technology, Jordan

\begin{abstract}
This study aims at showing the role of corporate governance in facing corruption for its great importance in various economic sectors. The study utilizes the descriptive approach to reach the final outcomes. The study concludes that the application of corporate governance leads to achieving many benefits for companies through the rationalization of the work of managers, the board of directors, the workers, and auditors, which ultimately leads to achieving the goals of governance in reducing corruption. The proper application of laws and financial regulations contributes to reducing corruption and conflicts of interest in a manner that guarantees the rights of shareholders and all other rights related to the company. On the other hand, failure to comply with the application of laws and financial regulations creates a fertile environment for corruption.
\end{abstract}

Keywords: Governance, Companies, Corruption, Stakeholders. 
المقدمة

كما هو معروف فان مفهوم الحوكمة يعد من ابرز واهم الموضوعات التي طرحت خلال السنوات الماضية، والتي تمس المؤسسات والمنظمات المختلفة، وقد زاد الاهتمام بتطبيق مبادئ الحوكمة في العديد من الدول خاصة بعد الأزمات المالية المختلفة التي

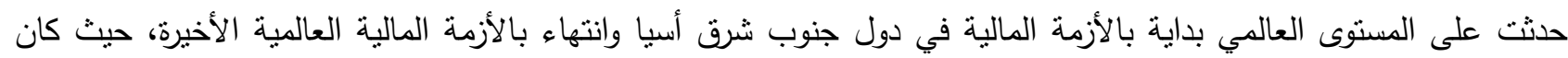
غياب أسس الحوكمة الرشيدة احد أهم أسباب حدوثها كما أثنارت العديد من الدراسات المتخصصة فئوبة في هذا المجال، فقد ساهم

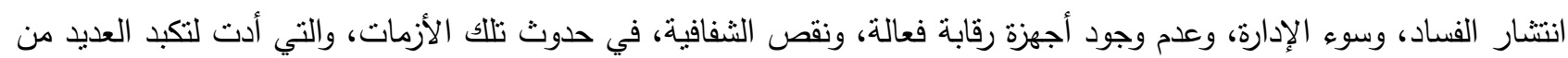

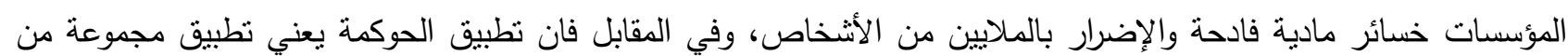
القواعد الإجرائية الهادفة لإجبار المؤسسات المالية على الالنزام بمعايير محددة من الثفافية والإفصاح وسلامة اختيار السياسات المالية مما يشكل درعاً واقياً لحدوث مثل تلك الأزمات مستقبلاً.

ونظراً لهذه الأهمية فقد حرصت الكثير من المؤسسات ومراكز البحث العالمية على دراسة مفهوم الحوكمة والآثار الناجمة عن الالتزام بمعاييرها المختلفة، ومن أهم تلكك المؤسسات صندوق النقد الدولي، والبنك الدولي، ومنظمة التعاون الاقتصادية والتتمية، وقد

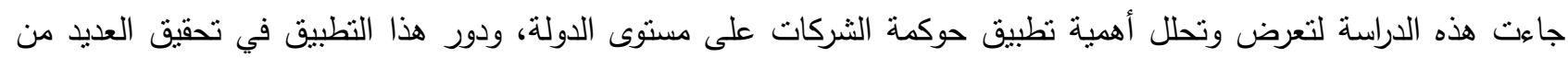
الأثار الإيجابية على الاقتصاد ككل، بما في ذلك دور الحوكمة في مكافحة الفساد، ورفع مستوى الأداء العام للاقتصاد.

أهداف البحث يهدف البحث إلى تحقيق جملة من الأهداف وهي:

1- التعرف على مفهوم حوكمة الثركات وماهيتها ونشأتها وخصائصها ومحدداتها. 2- التعرف على الجوانب الإيجابية ومزايا حوكمة الثركات، وكيفية الاستفادة منها من اجل تحسين أداء الثركات وفئات بشكل عام. 3- اظهار مدى اهية تطبيق مبادئ حوكمة الثركات في محاربة وتحجيم الفساد.

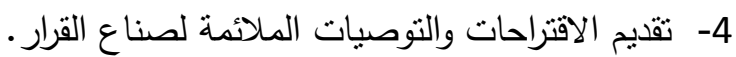

مشكلة البحث

تبذل الدول على اختلاف المستويات جهودا كبيرة في محاولة القضاء على الفساد، وفي سبيل ذلك فقد وضعت العديد من الخطط والسياسات الهادفة لاسنتصسال هذا الداء، وقد جاء هذا البحث لبيان الدور الذي من المدكن ان تسهم فيه حوكمة الثركات في ولي تحقيق هذا الهدف.

أهمبة البحث

يستمد هذا البحث أهميته من خلال أهمية الموضوع الذي يتطرق إلية والمتعلق بحوكمة الثركات، وبيان الدور الذي تساهم فيه حوكمة الثركات في تحقيق العديد من الفوائد وعلى راسها مكافحة الفساد، وذللك من خلال تعزيز دور الحوكمة في الثركات، كما لهابه

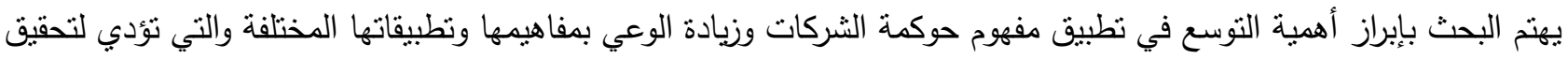
قدر كبير من الثفافية والعدالة في البيئة الاقتصادية داخل الدولة بالإضافة لدورها في تقليل المخاطر المرتبطة بالأعمال.

منهرية البحث

يعتدد البحث على المنهج الوصفي التحليلي لموضوع الدراسة، وهو منهج معمول به في الكثير من الدراسات والأبحاث خاصة تلك 
التي تتتاول ظواهر اجتماعية تتعلق بالممارسات اليومية، حيث سيتم الاستفادة من الدراسات والأبحاث العلمية والكتب والنشرات المتوفرة حول هذا الموضوع.

وفي سبيل تحقيق أهداف البحث فقد قسم البحث لمبحثين رئيسيين خصص الأول منهما للحديث عن الحوكمة بشكل عام من خلال

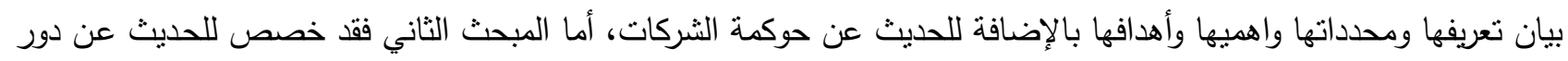
حوكمة الثركات في مكافحة الفساد ثم النتائج والتوصيات.

المبحث الأول: الحوكمة

تعريف الحوكمة

تثتير الأدبيات التي تحدثت عن الحوكمة إلى عدم الاتفاق بين الباحثين على تعريف محدد لها، وعلى الرغم من ذلك فقد اهتمت

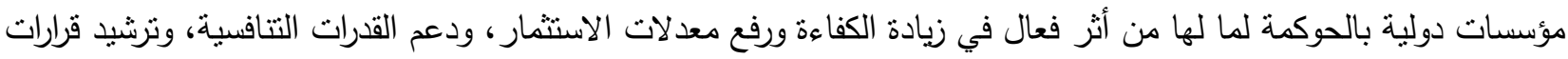
التمويل، ومضاعفة الأرباح والتتغيل، ومن هذه المؤسسات صندوق النقد الدولي، والبنك الدولي، ومنظمة التعاون الاقتصادي والتنمية (1).

والحوكمة Governance مشتقة من الكلمة الانجليزية Govern أي يحكم)(، وقد عرفت بمجموعة من التعريفات المتعددة، فالبعض عرفها على أنها "مجموعة العلاقات التي تجمع بين الإدارة التتفيذية للشركة ومجلس إدارتها من جهة، ومساهميها

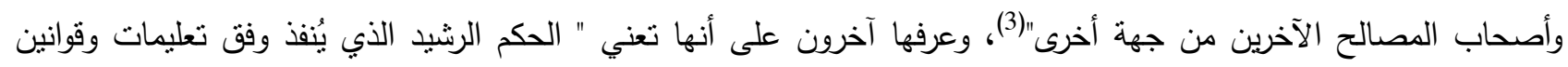

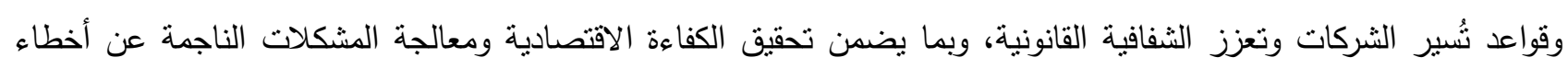
الإدارة والمراجعين"، أما مؤسسة التمويل الدولية IFC فقد عرفت الحوكمة على أنها "النظام الذي يتم من خلاله إدارة الثركات

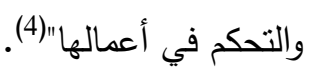

ومن خلال التعريفات السابقة نسنطيع القول بان الحوكمة تعني النظام الذي يحكم العلاقات بين الأطراف الأساسية التي تؤثر في أداء المؤسسة.

\section{نشأة حوكمة الشركات:}

ظهر مفهوم حوكمة الثركات بقوة حديثاً عام 1997، عقب انفجار الأزمة المالية الآسيوية وظهور أزمة الثقة في المؤسسات والتشريعات التي تتظم النشاط بين منشآت العمال. ونتيجة لذلك ظهر نظام حوكمة الثركات من خلال حرص عد عدد من المؤسسات

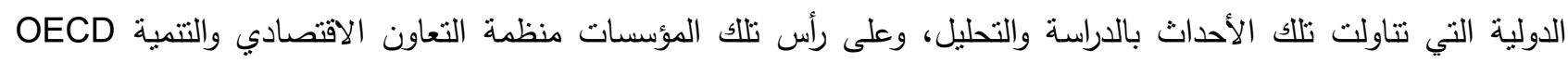
فأصدرت في عام 1999م "مبادئ حوكمة الشركات"، والني تهدف لمساعدة كل من الدول المشتركة والدول غير المشتركة بالمنظمة لتطوير الإطار القانوني والمؤسسي لتطبيق حوكمة الشركات لدعم إدارة الشركات في المحافظة على كفاءة واستقرار أسواق المال (5). وتقوم فلسفة الحوكمة في الثركات على مبدأ الفصل بين ملكية رأسمال الثركة والإدارة، وعملية الرقابة والإنشراف داخل هذه وفأ

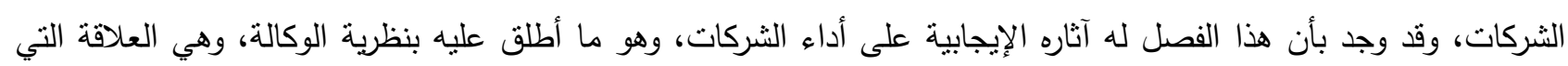

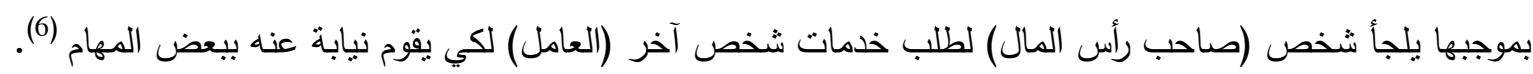

فوائد الحوكمة تهدف قواعد وضوابط الحوكمة إلى تحقيق الثفافية والعدالة ومنح حق مساعلة إدارة المؤسسة، وبالتالي تحقيق مصالح جميع

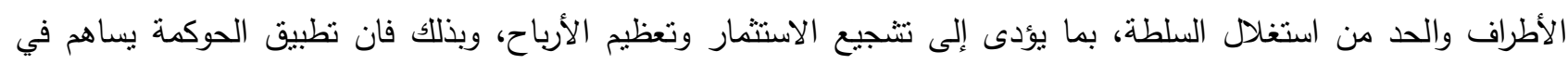
تحقيق مجموعة من الفوائد ويمكن تلخيصها بما يلي (7):--

- - تحقيق التتمية الاقتصادية من خلال توفير الطمأنينة للمستثرين وحملة الأسهم والحفاظ على حقوقهم. 
- - زيادة الثقة بالاقتصاد الوطني، وجذب الاستثمارات الأجنبية، وتشجيع رأس المال المحلي على الاستثمار .

- - تحسين الأداء المالي للشركات، من خلا الحفاظ على السمعة الاقتصادية للشركات، وتدعيم تنافسيتها في أسواق المال

العالمية، وحصولها على أعلى مراتب التقييم لدى مؤسسات الثقييم الدولية.

- - تعميق دور أسواق المال، وتوفير مصادر تمويل محلية وخارجية في تمويل المشاريع المختلفة.

- - تحقيق كفاءة استخدام الموارد المالية وتجنب الوقوع في مشاكل محاسبية ومالية.

- - منع حالات التلاعب والفساد وسوء الإدارة في الثركات، مما يؤدي إلى كسب ثقة المتعاملين معها ونجاحها في السوق.

- - مماية حقوق المساهمين ومصالحهم.

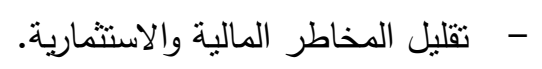

- - توفير فرص عمل جديدة.

- مراعاة مصالح العمال وعدم استغلال السلطة في غير الصالح العام.

وقد ظهرت الحاجة إلى الحوكمة في العديد من الدول خلال العقود الماضية، خاصة في أعقاب الأزمات المالية التي عصفت

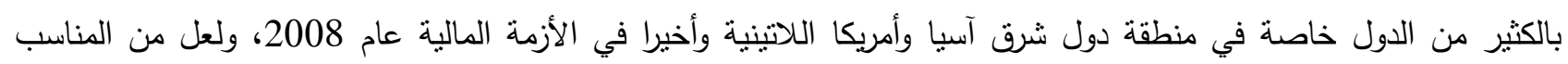

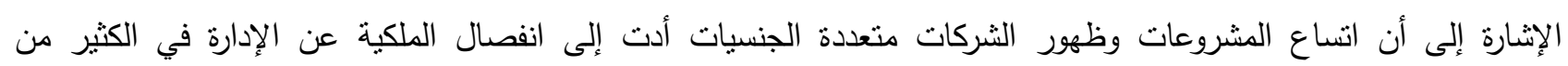

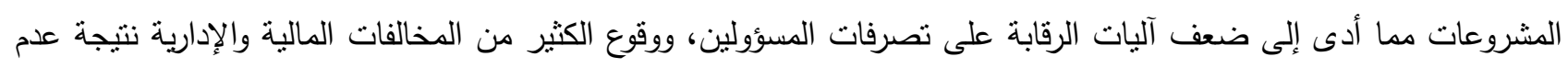
وجود رقابة فعالة، الأمر الذي دفع العالم للاهنمام بالحوكمة، وذلك كون قواعد وضوابط الحوكمة نساعد في تحقيق الثفافية

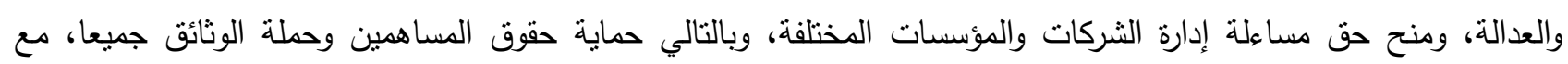
مراعاة مصالح العمل والعمال (8).

أهمية حوكمة الثركات:

من أهم مزايا تطبيق حوكمة الثركات قبامها بتيسير الحصول على التمويل (أسهم، سندات، ائتمان) وبتكلفة أقل، وزيادة الجذب

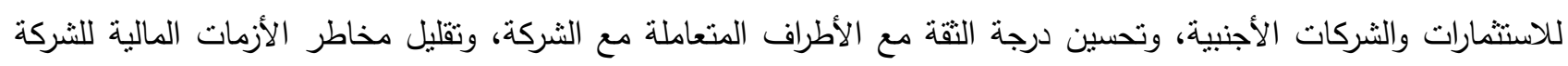

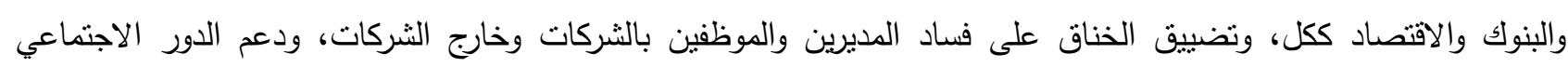

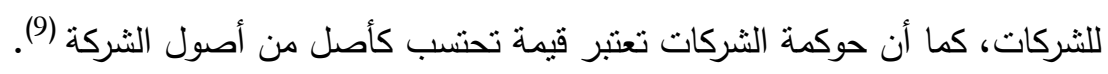
وعلى هذا يمكن القول إن حوكمة الثركات ثقدم مزايا لكل من المجتمع وللثركات وللمستثمرين. فمزايا حوكمة الثركات بالنسبة للمجتمع: هي تتجيع الاستثمار والتتمية المستدامة، ومحاربة الفساد، وتشجيع التتافس، كما تشجع على زيادة الإنتاجية والابتكار ، والعمل بكفاءة وتقليل الفاقد، كما تحافظ على استقرار الأسواق المالية وتتمي أسواق المال، وتتجع على فيام علاقات تتمتع بالثنفافية بين أصحاب الأعمال والدولة.

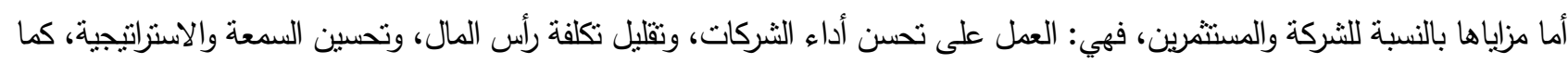
أنها تبني علاقات قوية بين أصحاب المصلحة، وتحمي حقوق المستثرين، وتقوم بتخفيف آثار المخاطر ، وتقوم بزيادة السيولة (10).

أهمية حوكمة الثركات من الناحية القانونية:

يعتبر القانون بصفة عامة من أهم الآليات التي نساعد على حوكمة الشركات، وخاصةة قوانين الشركات والقوانين التجارية، حيث

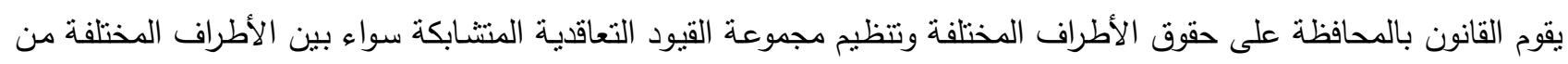
مؤسسين ومسـاهمين ومجلس الإدارة والإدارة العليا والموظفين بداخل الثـركة، أو الأطراف المختلفـة خـارج الثـركة كالمستنهلكين والموردين والدائنين والوكلاء والمنافسين والبنوك والجهات الإدارية والدول والبيئة الطبيعية وغيرها من الأطراف المختلفة بالمجتمع. 
كما أنه في ظل هيمنة نظام العولمة على الأسواق الداخلية والخارجية يمكن أن تصبح حوكمة الثركات حصان طروادة الذب يمكن

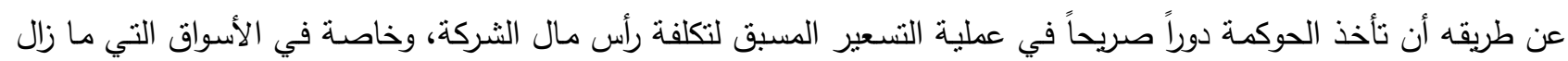
تمويل الثركات فيها محدوداً (11). أهمية الحوكمة من الناحية الاجتماعية:

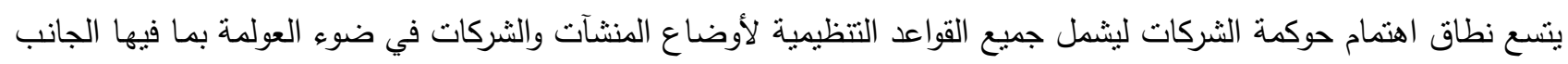

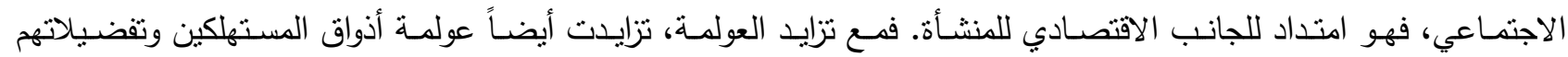
وميولاتهم الاجتماعية، والتي تؤثز في أعمال الشركة بتكلفة محسوسة، وعلى هذا لا يمكن أن يسمح النظام العالمي للشركات أن

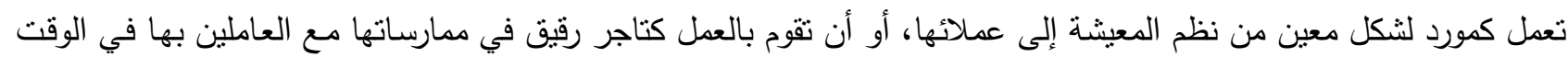

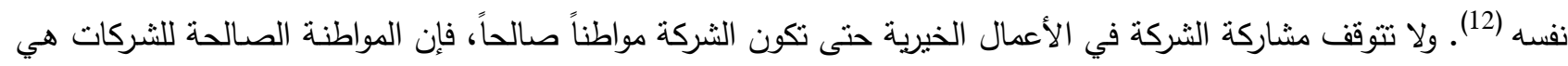
ما تؤدي إلى تحقيق الرخاء والازدهار للشركة، كما أنها في الوقت نفسه تسهم في خلق مجتمعات أفضل، وحماية حقوق الإنسان،

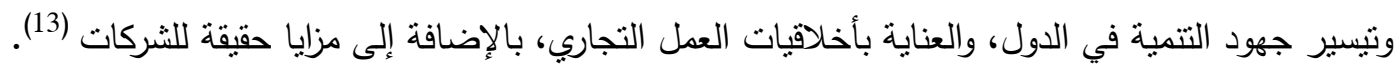

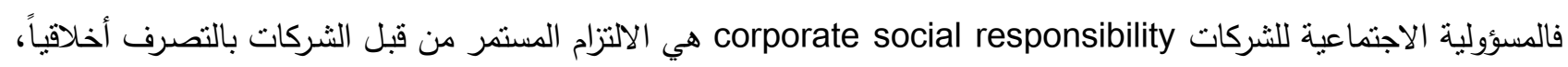

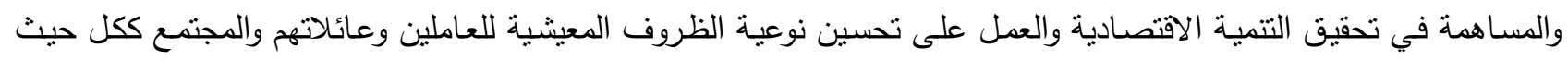

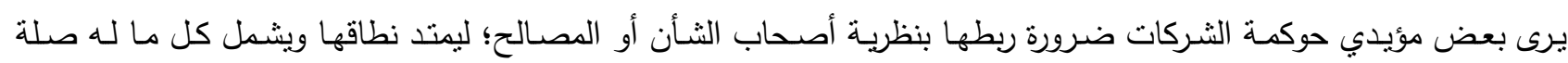
بالثركة والمجتمع ككل (14). ومن أهم الإسهامات التي تستطيع أي شركة في أي بلد أو قطاع صناعي أن تقدمها للمجتمع، هي بناء رأس المال البشري

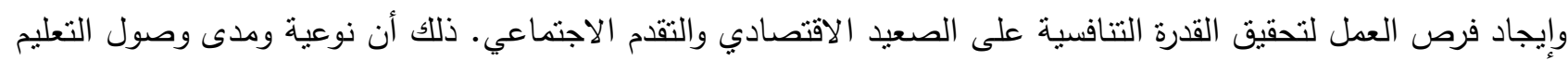

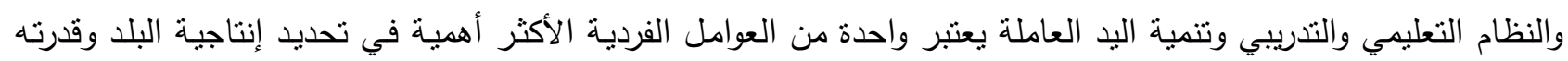
التنافسية، ونموه الاقتصادي، وازدهاره، وقدرته على توفير وظائف وظروف عمل لائقة، والتقدم الاجتماعي لمواطنيه. وتبرز

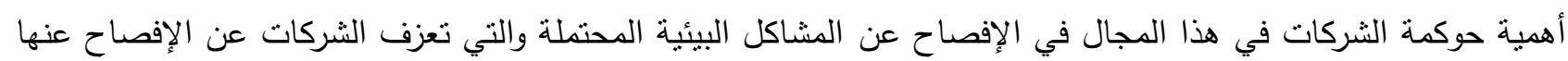

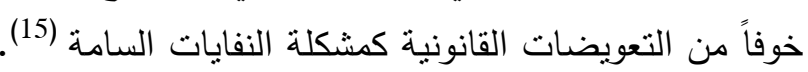

مبادئ حوكمة الشركات:

مبادئ الحوكمة هي المبادئ التي أقرتها منظمة التعاون الاقتصادي والتتمية OECD عام 1999م، وهي خمسية ونسة مبادئ اختبارية

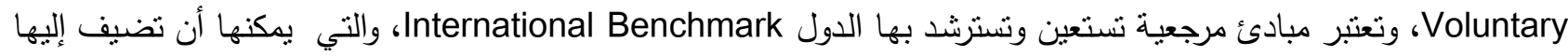
ما تحتاج إليه حسب ظروفها من مبادئ جديدة، وقد نم إعداد هذه المبادئ في الاجتماع الوزاري للاول والأطراف في المنظمة في الفترة من 27 إلى 28 إبريل 1998، وفي هذا الاجتماع طلب مجلس المنظمة ذاتها، أن تقوم بالاتشتراك مع الحكومات الوطنية

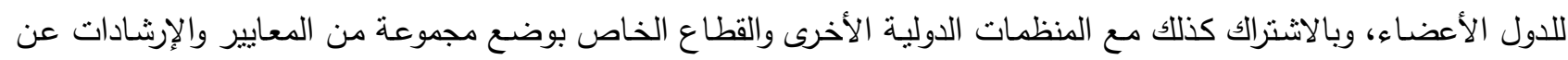
حوكمة الثركات. وتحقيقاً لهذه الدعوة، شكلت المنظمة فريق عمل مخصص لمهمة وضع مبادئ غير ملزمة لحوكمة الثركات تمنل وجهة نظر الدول الأعضاء في هذا الصدد (16). وهذه المبادئ هي عبارة عن معايير تقاس في ضونئها مدى تطبيق وتقدم الحوكمة في أي دولة من الدول، فكلما كانت المبادئ

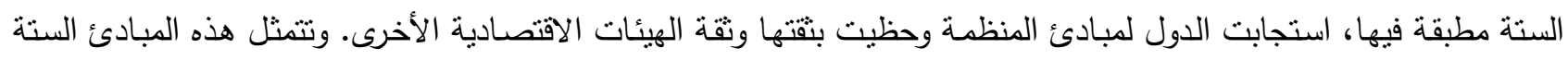
في: ضمان وجود أساس لإطار فعال لحوكمة الشركات، وحقوق المساهمين والوظائف الرئيسية لأصحاب حقوق الملكية، المعاملة

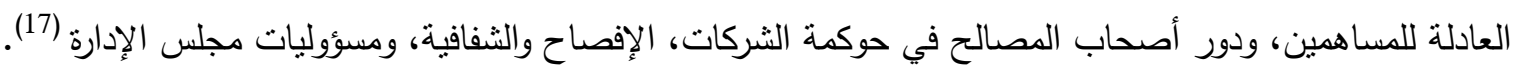

المبدأ الأول: ضمان ويود أساس لإطار فعال لحوكمة الشركات:

توصي منظمة التعاون الاقتصادي والتتمية في هذا المبدأ بضرورة وجود إطار فعال لحوكمة الثركات بحيث يكون هذات الإطار ذا تأثثر على الداء الاقتصـادي الثـامل ونزاهـة السوق، ويكون هذا الإطـار قـادراً على تكوين أسـواق ماليـة تتسم بالثـفافية 


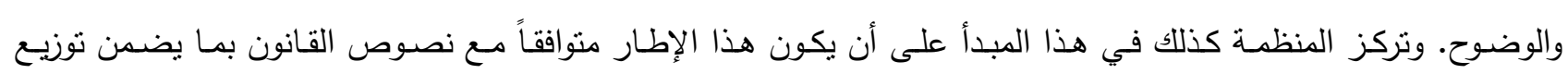
المسؤوليات بين مختلف الجهات (18). وتثدد المنظمة في هذا الإطار على ضرورة أن ينت نطوير هيكل الحوكمة مع مراعاة نأثنرها على الاقتصاد الكلي، ونزاهة السوق

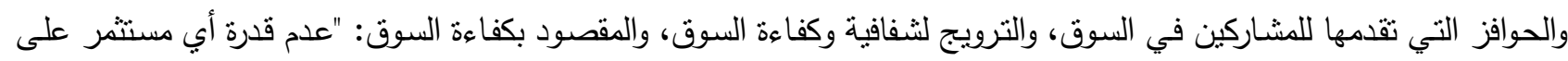

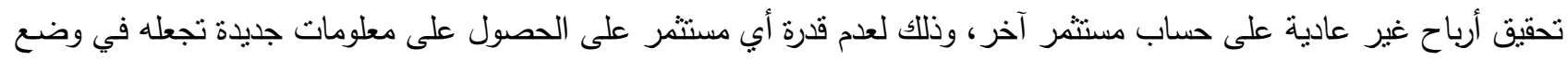

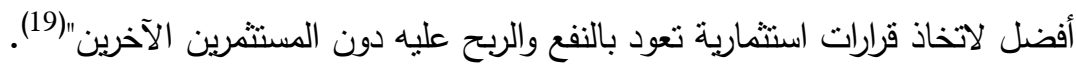

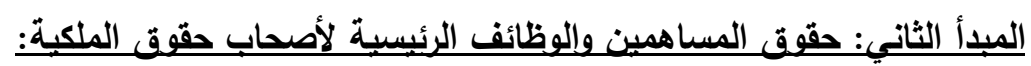
تؤكد المنظمة في هذا المبدأ على حقوق المساهمين العديدة التي تتمثل في التداول والثراء والبيع والتحويل وغيرها. وتضع المنظمـة

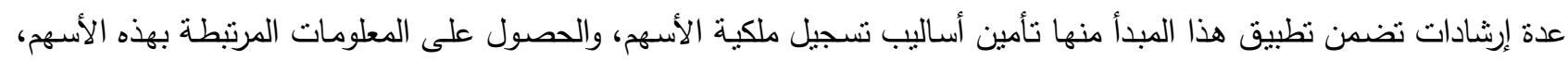

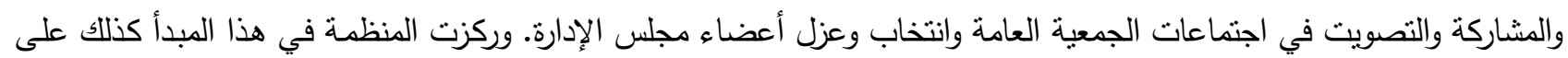

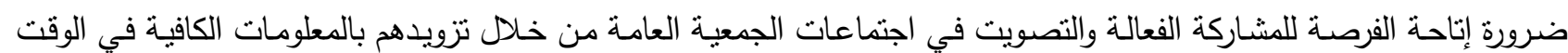
المناسب، وحق توجيه الأسئلة لأعضاء المجلس (20).

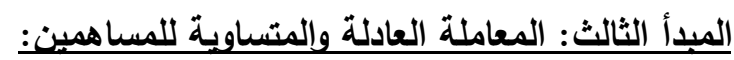
تشجيعاً للاستثمار الأجنبي وتأكيد ثقة المستثرين، جاء هذا المبدأ الثالث لتأكيد حماية رأس مال الثركة من جانب الأطراف ذات

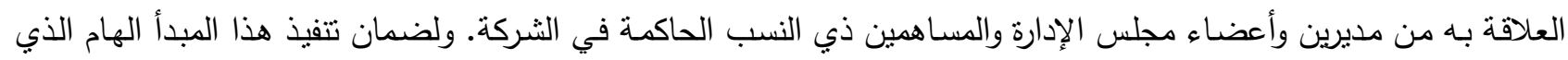

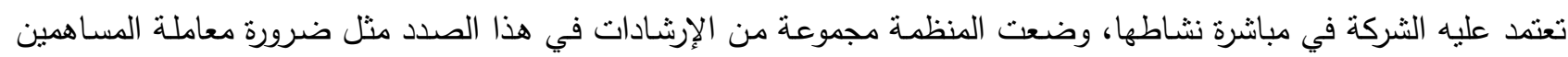
بطريقة منساوية دون محاباة للبعض على حساب البعض بحيث تكون للمساهمين من الطبقة الواحدة ذات الحقوق، وأن ينت الإدلاء

بالأصوات وفرزها عن طريق أمناء محايدين، وأن يسمح للمساهمين بنظام التصويت عبر الحدود دون عوائق (21). المبدأ الرابع: دور أصحاب المصالح في حوكمة الثركات: تهدف المنظمة من هذا المبدأ إلى تتجيع أصحاب المصالح في الثركة على الاستثمار في رأس مالها، ولأجل هذا فقد وضعت

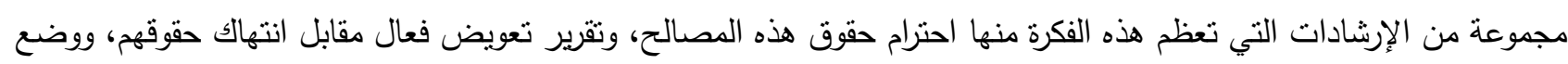

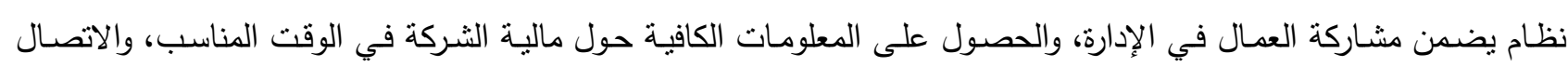
المباثر بأعضاء مجلس الإدارة والتعبير عن وجهة نظرهم في بعض الإدارة، والمسائل المتعلقة في إدارة الثركة وماليتها(22).

\section{المبدأ الخامس: الإفصاح والثفافية:}

يعتبر هذا المبدأ أهم مبادئ الحوكمة التي ركزت عليها المنظمة؛ لأنه بدون الإفصاح والثفافية في البيانات الصادرة عن الثركة لن

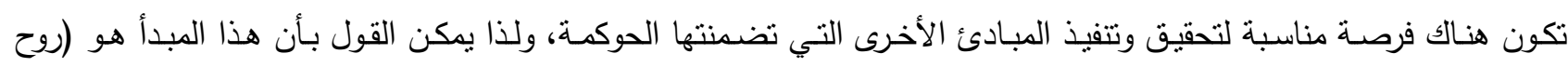

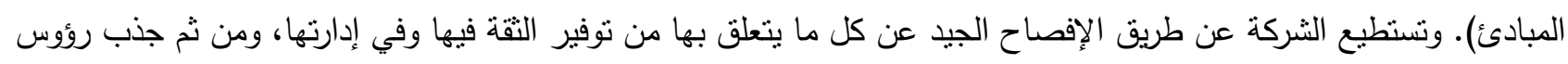

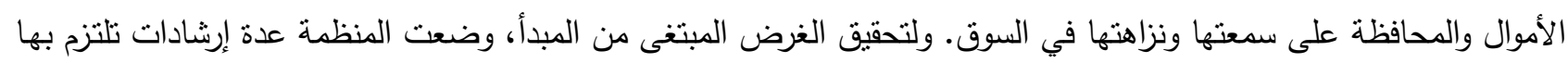

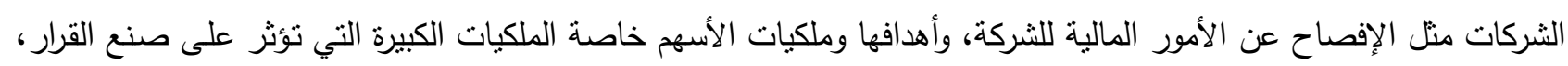

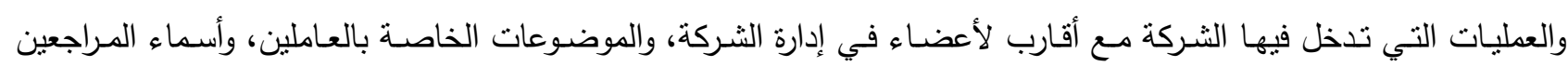
الخارجيين للشركة (23).

\section{المبدأ السادس: مسؤوليات مجلس الإدارة:}

لضمان اعتتاء أعضاء مجلس الإدارة بمهامهم ومسؤولياتهم، وضعت المنظمة مبدأ خاصاً بمسؤوليات مجلس الإدارة والعقوبات التي

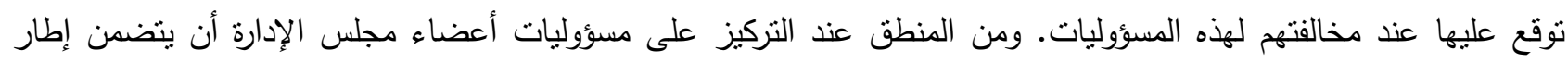

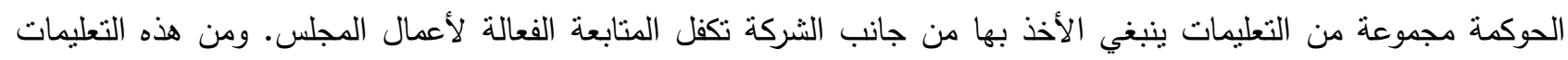

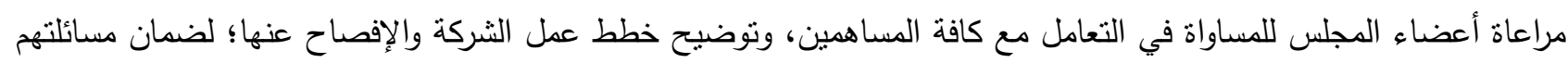
عند عدم تتفيذها، وتوضيح نظام المكافآت التي يستحقها أعضاء المجلس عن أعمالهم والأساس الذي تحسب عليه هذه المكافآت، 
وضمان الثفافية في اختيار أعضاء المجلس بحيث يشترك كل المساهمين في الاختيار، ضرورة تعيين أعضاء مجلس إدارة من غير موظفي الشركة والذين يطلق عليهم الأعضاء غير التنفيذيين الذين يمكهم الحكم المستقل على أداء مجلس الإدارة (24). المبحث الثاني: دور حوكمة الثركات في مكافحة الفساد

اولاً: تعريف الفساد واسببابه وآثاره. لا يوجد اتفاق بين الكتاب والمنظمات المعنية بمكافحة الفساد على تعريف محدد للفساد، فقد عرفه بعضهم بانه (اساءة استخدام السلطة العامة او الوظيفة العامة لأهداف خاصة) (25)، وعرفه اخرون بانه (اساءة استعمال الادوار او الموارد العامة للفائدة الخاصة) (26)، اما البنك الدولي فقد عرف الفساد (سوء استغلال السلطة العامة من اجل الحصول على مكاسب شخصية) (27)، في حين عرفت منظمة الثفافية الدولية الفساد بأنه (اساءة استعمال السلطة الموكلة لتحقيق مكاسب خاصة) (28). وعموماً يمكن القول بان مفهوم الفساد يغطي مجموعة واسعة من الممارسات السياسية والاقتصادية والادارية المشبوهة والمريبة،

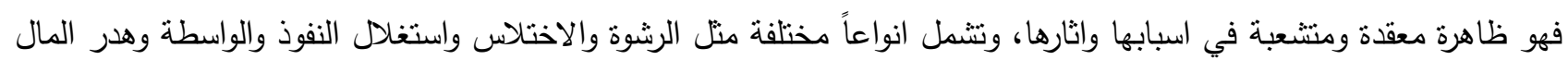
العام (29). وللفساد اسباب متشعبة ومتداخلة ومعقدة اهمها (30):1- ضعف البناء القيمي وضعف الضوابط الاخلاقية في المجنمع، وهي ما يطلق عليها الاسباب التربوية والسلوكية للفساد، مما يؤدي الى تغليب مصلحة الفرد على المصلحة العامة. 2- تردي الظروف الاقتصادية والاجتماعية (الاسباب الاقتصادية) مما يؤدي الى توجه الافراد لأي مصدر دخل ممكن لتحسين ظروفه المعيشية.

$$
\text { 3- غياب سلطة المساءلة، وضعف الجانب الرقابي والقانوني. }
$$

4- غياب العدالة بين افراد المجتمع وشعور بعض الافراد بالغبن مما يدفعهم للحصول على حقوقهم التي يشعرون انها اخذت

$$
\text { منهم بطرق غير مشروعة. }
$$

5- عدم كفاءة ونزاهة القيادات العليا في الدولة، فمعظم عمليات الفساد الكبرى تتم من خلال هذه الفئات.

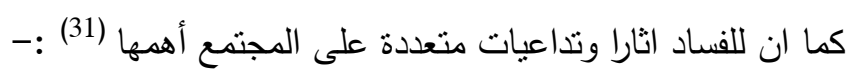
1- - زعزعة الاستقرار الاقتصادي في الدولة.

2- 2 عرقلة النمو وزيادة نسب الفقر والعجز عن مكافحته. 3- عجز الدولة عن تقديم الخدمات. 4- - زعزعة الثقة بنظام الحكم في الدولة. 5- زيادة نسبة البطالة. 6- خفض معدلات الاستثمار لارتفاع تكلفة الاستثمارات نتيجة دفع الرشاوى. 7- الحد من المنافسة المشروعة بين الافراد والمؤسسات. 8- عزوف الدول المانحة عن تقديم المعونات والمساعدات. 
يعد الفساد المالي والإداري من اخطر المشكلات التي تعاني منها مؤسسات الدولة بصفة عامة، ويتمثل هذا الفساد بالامنيازات والمكاسب التي يتم الحصول عليها بصورة غير قانونية، وقد ادت الانهيارات المالية والفضائح الادارية التي حصلت في الاعوام

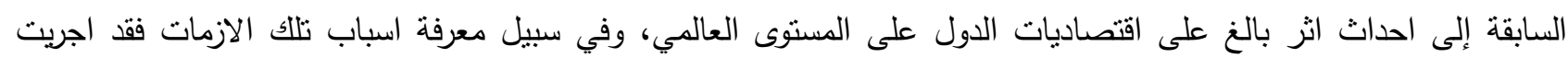

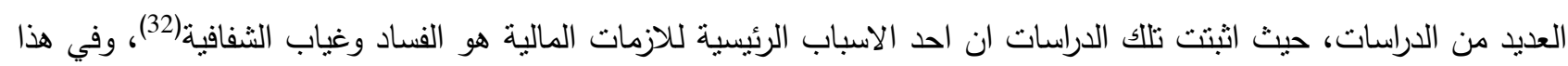
المبحث سنقوم ببيان دور الحوكمة في مكافحة الفساد.

ومما لا شك فيه ان تطبيق الحوكمة من شأنه ان يكفل تجاوز العديد من السلبيات التي تؤدي لحدوث الفساد في الثركات، وذلك من خلال مجموعة من اليات المتعلقة بإحكام الرقابة في الثركات، وتحقيق مصالح كافة الاطراف ويتم ذلك من خلال الإنه الاجراءات

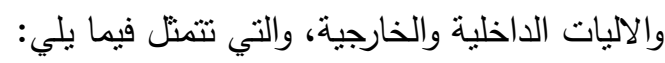

1 - 1 - الاليات الداخلية: حيث تتمنل هذه اليات في حوكمة انشطة وفعاليات الثركة الداخلية، واتخاذ القرارات التي تهدف لتحقيق اهداف الثركة الداخلية، ويمكن تصنيف هذه الاليات الى ما يلي (33):

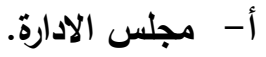

يعتبر مجلس الادارة من اهم ادوات الرقابة الفعالة على ادارة الثركة، كونه يتمتع بصلاحيات تعيين واعفاء ومكافئات الادارة العليا

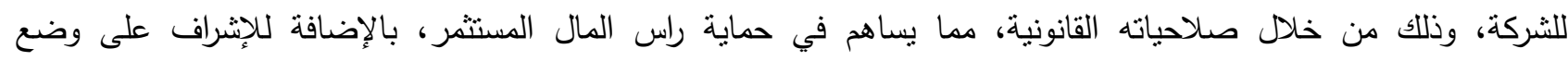
استراتيجية الثركة، شريطة ان تتم تلك الاجراءات بنزاهة وحكمة لتحقيق اهداف الثركة.

ولكي يتمكن مجلس الادارة من القيام بالمهام المطلوبة منه بفعالية فانة يشكل لجان من أعضاءه للقيام بمهام تخدم الثركة وهذه اللجان هي:

1- لجنة التحقيق: وهي لجنة متخصصة في اعداد التقارير المالية للشركة، كما انها تشرف على وظيفة التدقيق الداخلي، بالإضافة لدورها في التأكيد على الالتزام بمبادئ حوكمة الثركات، مما يساهم في زيادة الثقة والثفافية في المعلومات المالية.

2- لجنة المكافآت: وهي لجنة مشكلة من مجلس الادارة، لتحديد المكافآت المصروفة على ان تكون معقولة وتتناسب مع حجم الانجاز.

3- لجنة التعيينات: وهي لجنة متخصصة في المفاضلة بين المرشحين للعمل في الثركة، وخاصة الوظائف العليا، والاطلاع على مهاراتهم وخبراتهم لضمان الثفافية في التعيين. ب-التدقيق الاخلي.

تؤدي وظيفة التنقيق الداخلي دوراً مهماً في ارسال قواعد الحوكمة في الثركة، حيث تسهم هذه العملية في زيادة المصداقية

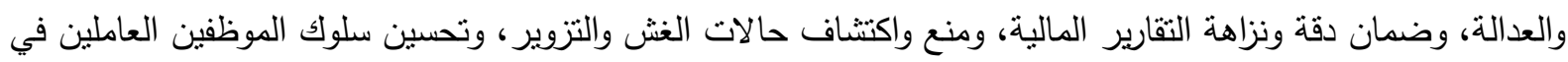

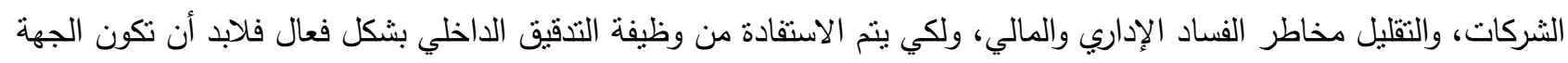
المسؤولة عن ذلك مستقلة ومنظمة بشكل جيد.

\section{2- الآليات الخارجية (34).}

وتتمنل هذه الاليات بالرقابة التي يمارسها أصحاب المصالح الخارجيين على انشطة الشركة المختلفة، حيث تشكل هذا الاليات مصدر ضغط على الشركة لتطبيق قواعد الحوكمة، ومن هذه الاليات: 
حيث تتير الدراسات الحديثة في هذا المضمار الى ان الإدارة التي تفشل في تطبيق اسس الحوكمة ومنافسة الثركات في نفس القطاع فإنها سوف تتعرص للإفلاس، مما يحتم على الادارة العليا للشركة لاختبار افضل الطرق والاساليب الادارية والانتاجية لمواجهه ذلك.

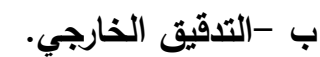
يؤدي المدقق الخارجي دوراً مههاً في المساهمة في تحسين اداء الثركة بشكل عام، لذا فان عملية اختبار المدقق الخارجي الكفؤ والمتخصص تعتبر من اهم اسس نجاح الرقابة الخارجية، كما ان عملية التدقيق الخارجي تساهم في تحقيق المساءلة والنزاهة وتحسين العمليات في الثركة، حيث يتم ذلك من خلال عمليات التدقيق المالي، وتدقيق الأداء.

ج-التشريع والقوانين.

تساهم الانظمة والقوانين في اجبار الادارة العليا على تطبيق اسس الحوكمة، وتقوية إثراف جهات التدقيق المختلفة على عملية إعداد التقارير المالية.

د - الجهات الرقابية الدولية.

هناك العديد من الجهات الرقابية الدولية التي تفرض رقابة على عمل الثركات والمؤسسات واجبارها على تطبيق اسس الحوكمة ومحاربة الفساد الاداري والمالي، ومن هذه المؤسسات منظمة الثفافية العالمية، ومنظمة التجارة العالمية، ولجنة بازل.

\section{الخلاصة}

يمكن القول ان تطبيق حوكمة الثركات يؤدي إلى تحقيق العديد من المنافع للشركة، وذلك من خلال ترشيد اعمال المديرين

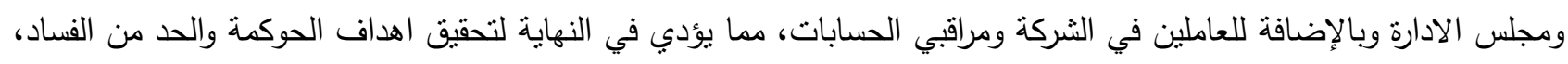

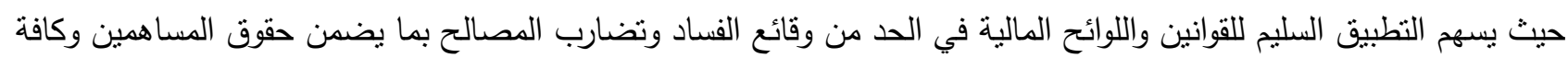
الحقوق الأخرى ذات العلاقة بالثركة، وفي المقابل فان عدم الالتزام بنطبيق القوانين واللوائح سوف يؤدي الى خلق بيئة خئة خصبة لنمو الفساد وتنلغله وعدم القدرة على مواجنته.

1- على الرغم من أهمية حوكمة الثركات إلا ان هناك اختلافا وعدم اتفاق بين الباحثين فيما يتعلق بمفهوم الحوكمة. 2- زاد الاهتمام بحوكمة الثركات خاصة بعد الأزمات المالية التي حثث وكان آخرها الأزمة المالية العالمبة عام 2008. 3- يعتبر تطبيق الحوكمة من الضمانات الرئيسية لأصحاب الحقوق والمصالح في داخل الشركات. 4- هناك أثز وأهمية واضحة لنطبيق حوكمة الثركات لصالح الأفراد والمؤسسات والمجتمعات في العديد من النواحي الاقتصادية والقانونية والاجنماعية. 5- يساعد تطبيق حوكمة الثركات في تحقيق العديد من الاهداف واهمها مكافحة الفساد.

التوصيات: في ضوء نتائج هذه الدراسة يمكن استخلاص التوصيات التالية: 1- لابد من إلزام الثركات بتطبيق أسس الحوكمة والإفصاح، وذلك للفوائد الجمة التي تعود على الاقتصاد نتيجة لذلك.

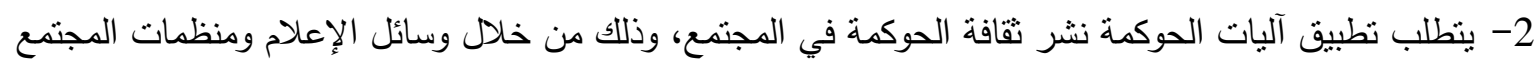

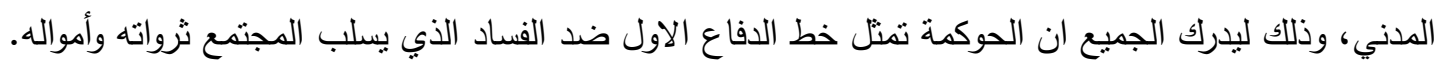
3- نشر الوعي الفكري في المجتمع واعتبار محاربة الفساد مهمة وطنية يشارك فيها الجميع، كلاً حسب موقعة. 
4- اصدار قوانين وعقوبات صارمة بحق مرتكبي الفساد.

5- تشجيع الدراسات المتعلقة بالحوكمة ومكافحة الفساد.

المراجع

(11) نسمان، احمد، مراجعة تطبقات الحوكمة في القطاع المصفي المصري، القاهرة، دار عصمت، الطبعة الأولى، 2012، ص9.

(2) الحمصي، رياض، الحوكمة والأسولق المالبة، بيروت، دار الثام للنشر، الطبعة الأولى، 2009، ص 23. (3) فوزي، سميحة، الحوكمة المصرفية الأسس والمبادئ، القاهرة، دار شباب الجامعة للنشر، ، الطبعة الأولى، 2000 ، ص ص 11. ( ) قباحة، عبد المجيد، أواقع الحوكمة في المؤسسات المالبة القلسطينية، بحث مقدم لمؤتمر الحوكمة المصرفية،2010، القاهرة، ص 19. (5) موسى، رمزي، حوكمة الشركات في القرن الحادي والعشرون، مؤتمر المؤسسات المالية بعد الأزمة المالية العالمية، الجزائر، 2013، ص مونسي 8

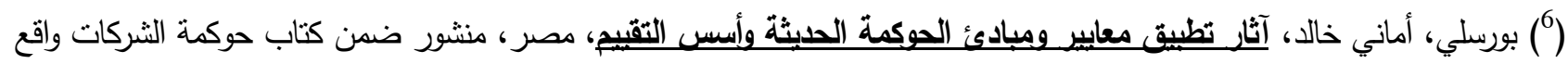

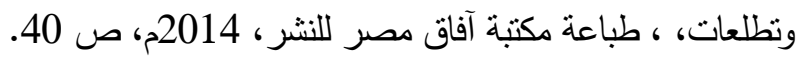
( ) جودة، عبد الغني، حوكمة الثركات ودورها في التقليل من التضليل في الأسولق المالبة، مؤتمر الحوكمة المصرفية، دبي 2011، ص 14. ( (8) أبو حمام، إسماعيل ، الحوكمة في الثركات، بيروت، دار الأمل للنشر، 2010، الطبعة الأولى، ص 24.

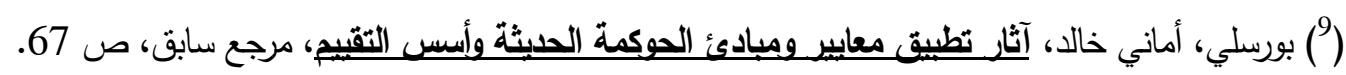

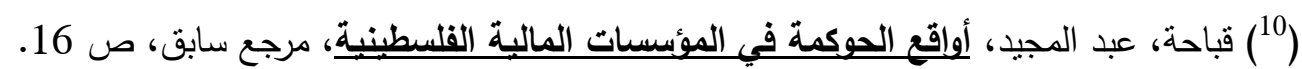

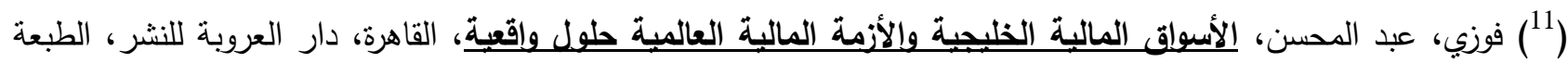

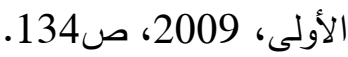
(12) أبو حمام، إسماعيل ، الحوكمة في الثركات، مرجع سابق، ص صدات 29.

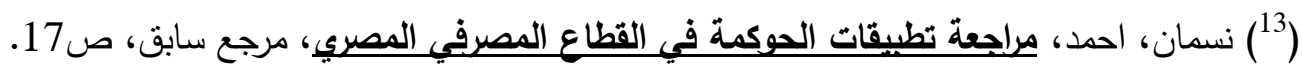
(14) الثهيلي، رحاب، الأزمة المالبة العالمبة 2008 وأثثارها على الدول النامبة، مؤنتر الأزمة المالية العالمية وأثراها،

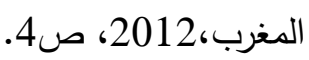
(15) نجم، عبود نجم، أخلاقيات الإدارة ومسؤوليات الأعمال في شركات الأعمال، الأردن، دار الوراق، الطبعة الأولى، عام 2006م، ص 128. (16) نجم، عبود نجم، أخلاقيات الإدارة ومسؤوليات الأعمال في شركات الأعمال، مرجع سابق، ص430. ( $\left.{ }^{17}\right)^{17}$

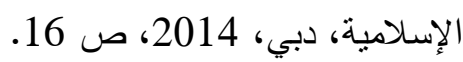
(18) الدراوشة، عصام، واقع الحوكمة في المؤسسات المالية الإسلامية، بيروت، دار الساحة للنشر، الطبعة الأولى، 2010، ص82.

(19) العزايزة، سعيد، الحوكمة كمعالجة للأزمة المالبة العالمبة، الرياض، دار الرحاب، الطبعة الأولى، 2013، ص 79.

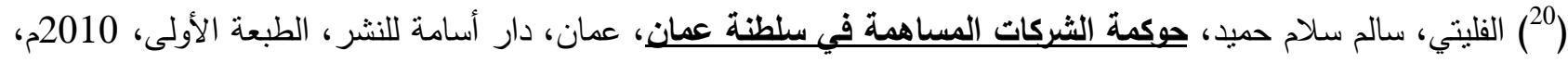

( (21) سليمان، إبراهيم، الثركات المساهمة ما بين الحوكمة والأنظمة والتعليمات الحالية، مرجع سابق، ص 19.

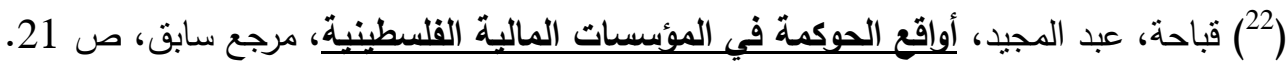


( $\left.{ }^{23}\right)^{23}$ ص 167.

( $\left.{ }^{24}\right)^{24}$ نسمان، احمد، مراجعة تطيقات الحوكمة في القطاع المصرفي المصري، مرجع سابق، ص 20.

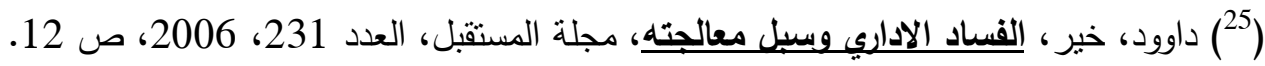
(26) عبد الفضيل، خير الله، الفساد الاداري والمالي بين السباسات والاجراعات، مجلة الادارة العربية، مجلد 19، العدد 1، 2009، ص18 (27) الثربجي، خالد ، الفساد الاداري ومعالجته، بحث مقدم لمؤتمر منظومة النزاهة ومكافحة الفساد، قطر ، 2010، ص 4.

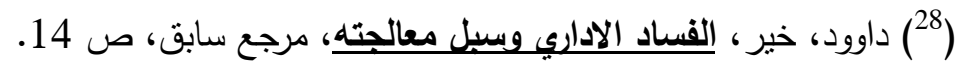

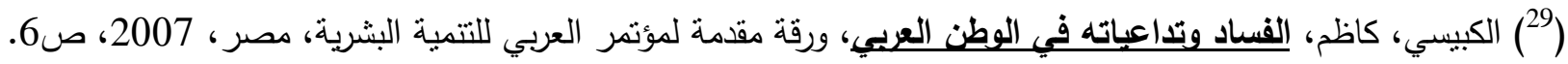

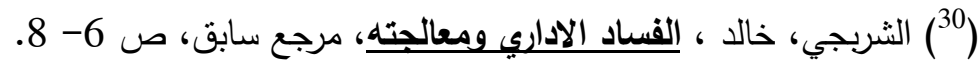

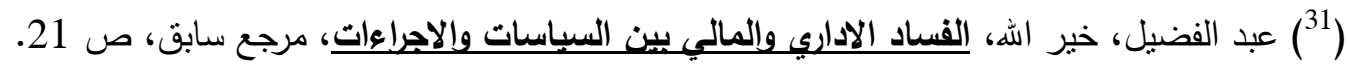

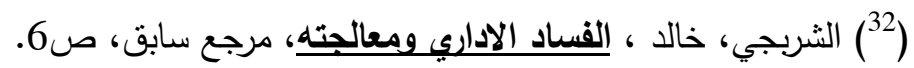

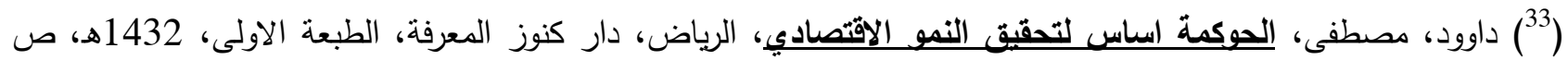
$.79-63$ (43) ادم، علي، الحوكمة وتحقيق التنمية الاقتصادية، القاهرة، الدار الجامعية، الطبعة الاولى، 2007، ص 113-128. 